\title{
Modeling of the Missile Launch Dynamic Processes in Short-Range Air Defense System
}

\author{
Algimantas FEDARAVIČIUS*, Karolis JASAS**, Egidijus SLIŽYS***, \\ Arvydas SURVILA***** \\ *Kaunas University of Technology, Studentu 56, 51424, Kaunas, Lithuania, E-mail: algimantas.fedaravicius@ktu.lt \\ **Kaunas University of Technology, Studentu 56, 51424, Kaunas, Lithuania, E-mail: karolis.jasas@ktu.lt \\ ***Kaunas University of Technology, Studentu 56, 51424, Kaunas, Lithuania, E-mail: e.slizys@ gmail.com \\ ****Kaunas University of Technology, Studentu 56, 51424, Kaunas, Lithuania, E-mail: arvydas.survila@ktu.lt \\ crossref http://dx.doi.org/10.5755/j02.mech.29266
}

\section{Introduction}

A short-range air defense system is an effective tool for the state defense against low flying air targets such as helicopters or air attack aircraft. Most of the short-range air defense systems consist of a stand, a launcher and a missile. Training of short-range air defense systems operators is very important process to ensure state defense. In developing field training equipment for short-range air defense systems, it is very important to evaluate missile launch dynamic processes and to give the system operator the real shooting feelings. The simulator should give the real shooting feelings during the simulation of the combat shooting into real air targets, without using the real missiles. In this article, the first stage missile launches from the short-range air defense system RBS-70 was modeled. The researched missile launch dynamic model can be adapted for the other shortrange air defense systems, such as Stinger or GROM.

The RBS-70 system (Fig. 1) is a mobile anti-aircraft missile complex. The system consists of a stand 3, a sight 2 , and a container with a missile 1 . RBS-70 anti-aircraft missiles are constantly updating, i.e., increasing the missile flight distance. The stand has three legs and can be leveled by adjusting one of the legs. On the stand, the sight and the missile in the container were placed [1].

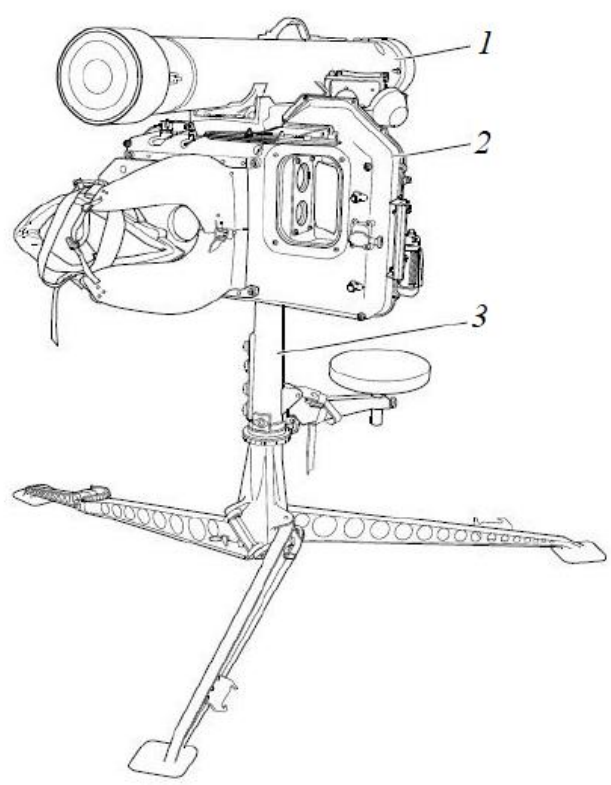

Fig. 1 RBS-70 short-range air defense system [1]
Another significant element of the system is the sight. It consists of two parts - the front, and the rear casing, which are sealed together. The casing of the sight has the function to withstand environmental stresses and provides a surface for other components mounting. The sight to the stand is attached by brackets and secured by the catch. The transmitter in the sight consists of a Laser Transmitter Unit, which has the function to generate the beam. The beam is transmitted by the Optical Unit. The zoom unit, which is a part of the Optics Unit, has the function to find the missile upon launching and subsequently zoom onto the target. This beam is then reflected by a Stabilized Mirror Unit and transmitted through the front sight window. The mirror can rotate around the azimuth axis and elevation axis. Two gyros are mounted to control the azimuth and elevation angles $[1,2]$.

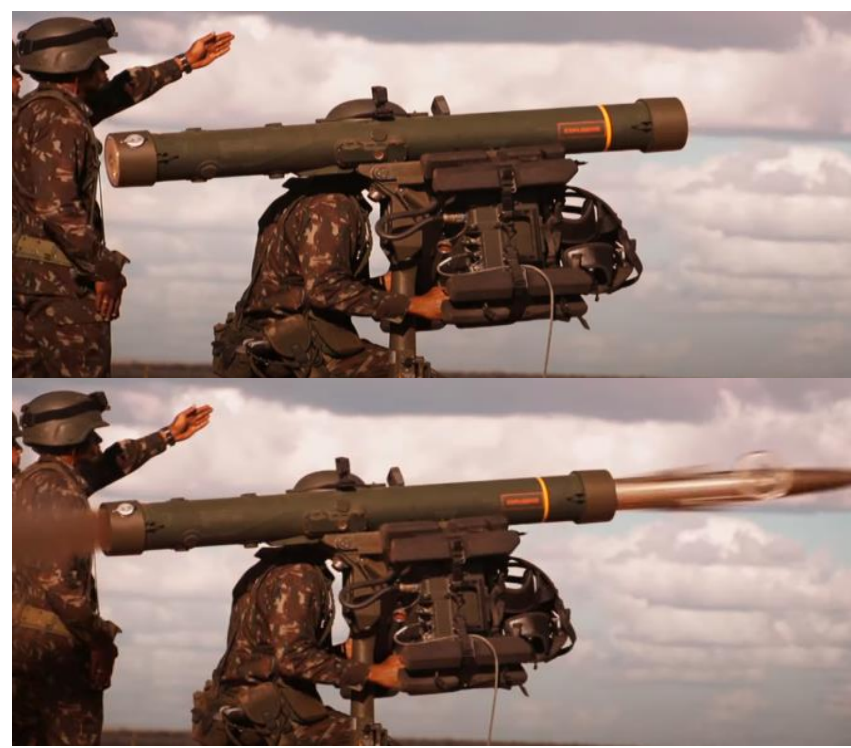

Fig. 2 RBS-70 first stage of the missile launch [3]

This article presents the modeling of the first stage of missile launch (Fig. 2). The short-range air defense system stands on a soil foundation. The stand is a solid body that can rotate along its axis. The missile launcher can move up or down with the help of hinges. After the application is fired, the missile moves longitudinally in the tube for some time. Ideally, the missiles in the launcher need to move straight. In practice, however, this is not possible due to the dynamics of the whole system. Engine thrust, launch and missile flexibility properties, joint characteristics, feather 
force, mass imbalance, and thrust mismatch affect the dynamics of the launch system. Since it is not possible to have such an ideal system, the design of this type of the system aims to have as few errors as possible. If errors arising from the boot system, the necessary precautions can be taken in advance [4].

In the first stage of the shot, the system operator sits on a rack-mounted chair and applies to the target. After the aiming of the target, the operator makes the shot. In the first shot stage, the engine of the missile is launched. The missile starts moving longitudinally in the missile container. The first stage ends when the missile leaves the container. This missile movement creates the vibrations and recoil of the launcher.

\section{Physical model for the first stage of missile launch}

The physical model based of the short-range air defense system RBS-70 has been developed (Fig. 3). The model presented in this figure illustrates the first phase of the missile launch motion.

The physical model of the anti-aircraft system was constructed on the basis of the classical mechanics. It consists of inertial elements in the form of material points, rigid bodies and inertial elements with reproducing and dispersing properties. Therefore, the formulated physical model of the anti-aircraft system should be assigned to the category of individual systems [5].

Flight path of the missile is formed according to the meaning of these parameters. Due to launcher motions, the missile may fly in an unfavorable trajectory and therefore not reach the target. It moves in gravitational field and atmosphere of the Earth's. The missile must be launched in such a way that it reaches the target with maximum accuracy. Launch conditions may vary. The differences are due to the different initial angles of the trajectory. Depending on these parameters, another point on the Earth's surface is reached. The wind is another factor that can affect the trajectory of a missile. The direction of the wind and its speed can vary, so the influence of these factors on the trajectory and point of fall of the missile also differs. Therefore, even if the initial conditions (i.e., the initial trajectory angles) are the same, the flight trajectories are different [6].

To formulate mathematical description of the missile motion, the following assumptions have been made:

1. The missile is a rigid body but its mass and moments of inertia change during the initial, active-flight portion of the trajectory;

2 . The missile has two symmetry planes. These are the $\mathrm{O}_{x z}$ and $\mathrm{O}_{x y}$ planes, which are the planes of geometric, mass and aerodynamic symmetries [6].

Typically, missile launch system consists of a missile launcher (including a vehicle or stand, a turntable, a step hull, and a launch tube) and a missile. The physical model used in this study is shown in Figure 3. In terms of launch dynamics, critical issues in simulating the dynamic characteristics of missiles and launch systems are focused on the following complex and hot spots: launching stiffness or flexibility control of the launch tube (or missile) [7].

The study assumes that the RBS-70 air defense system is mounted on an asymmetrically vertical plane passing through the center of mass. The system consists of three masses and two deformable elements. The sight is a completely rigid body with a mass $m_{v}$ and a moment of inertia
$I_{\mathrm{v}}$. There is a rotation between the missile and the sight. Deformable element has stiffness $k_{31}$ and damping $c_{31}$. The physical model shows the geometry of the sight characteristics required for the analysis of assembly dynamics. The stand is built on the ground using legs, which has two common deformable elements with stiffness $k_{11}, k_{12}$, and damping $c_{11}, c_{12}[8]$.

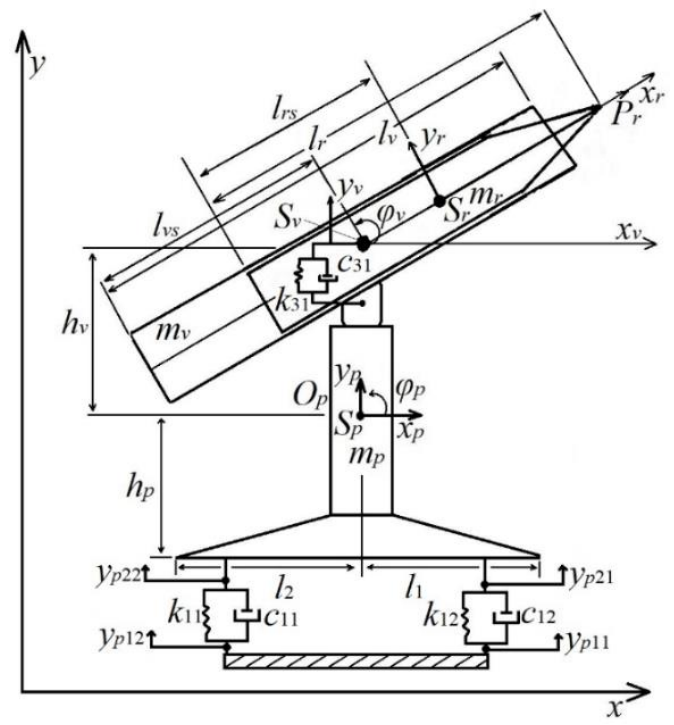

Fig. 3 Physical model of the launching first stage

When the missile is flying in the air, it turns and rotates about its axis. The rotation takes place at a point called the mass center of missile. The mass center is concentrated in the center of the missile [9].

The missile is an object whose mass and weight distribution are variable. Missile mass $m_{r}$ and moment of inertia $I_{r}$ are functions that change over time. The approximate time when the missile leaves the container is 0.05 seconds. For that reason, mass center of the missile is not evaluated in this model.

For a stand with mass $m_{p}$ and moment of inertia $I_{p}$ and sight with mass $m_{v}$ and moment of inertia $I_{v}$ the movement at a given time is determined according to the Cartesian dextrorse rectangular coordinate system [9]. Reference system for these coordinates:

1. coordinates defining movement of the stand: $\mathrm{O}_{p} x_{p} y_{p} z_{p}, S_{p} x_{p} y_{p} z_{p}, S_{p} x_{r} y_{r} z_{r}$.

2. coordinates defining movement of the sight: $\mathrm{O}_{\mathrm{v}} \mathrm{X}_{\mathrm{v}} \mathrm{y}_{\mathrm{v}} \mathrm{Z}_{\mathrm{v}}, S_{v} x_{v} y_{v} z_{v}, S_{v} x_{r} y_{r} z_{r}$.

The number of degrees of freedom of the formed launcher structural model describing initial movement in vertical plane is 3 . Two independent coordinates are included to determine the stand position with mass $m_{p}$ and moment of inertia $I_{p}$ at any time: $y_{p}$ - the vertical center of mass of platform $S_{p}, \varphi_{p}$ is the angle of rotation of the stand about the $S_{p} z_{p}$ axis. One independent generalized coordinate has been adopted to determine the positions of the starter with mass $m_{v}$ and moment of inertia $I_{v}$ at a given point in time: $\varphi_{v}$ - rotating about the axis $S_{v} z_{v}$.

Coordinates defining motion of the missile at launch from the launcher:

1. Coordinate system defining missile's take-off motion: Oxyz, $\mathrm{O}_{v} x_{v} y_{v} z_{v}, S_{v} x_{v} y_{v} z_{v}$, and $S_{v} x_{r} y_{r} z_{r}$ are the coordinate systems discussed earlier that define the motion of the trigger. In the case of the missile and the launcher, the coor- 
dinate system: $\mathrm{O} x y z, \mathrm{O}_{v} x_{v} y_{v} z_{v}, S_{v} x_{v} y_{v} z_{v}$, and $S_{v} x_{r} y_{r} z_{r}$ also defines the missile lifting motion.

2. Coordinate systems defining relative missile motion: $S_{r} x_{r} y_{r} z_{r}$ is a coordinate system that performs a linear motion relative to the coordinates $S_{v} x_{v} y_{v} z_{v}$. The start of the coordinate system $S_{r}$ coincides with the center of mass at any point in time. The condition of parallelism is always satisfied for the axes $S_{r} x_{r}\left\|S_{v} x_{r}, S_{r} y_{r}\right\| S_{v} y_{r}$, and $S_{r} z_{r} \| S_{v} z_{r}$, which correspond to each other. Due to the influence of the missile booster, the center of mass of the missile $S_{r}$ is displaced along the axis $S_{v} x_{r}$.

The $S_{r} x_{r}, S_{r} y_{r}$, and $S_{r} z_{r}$ axes are firmly connected to the missile hull in such a way that they become its main axes of inertia.

\section{Mathematical model for the first stage of missile launch}

Based on the physical model of the short-range air defense system, a mathematical model of the first stage of a missile launch was developed. The model describes the dynamics of the first stage - missile launch with differential equations. The model has been selected according to the methodology of De Silva, 2007 [9]. The idea of the methodology is that vibration is periodic or oscillating response of mechanical system. Four independent coordinates were adopted to determine the motion of the launch model:

a) stand - completely rigid body: $y_{p}, \varphi_{p}$; b) sight fully rigid housing: $\varphi_{v}$; c) missile - time-varying system: $x_{r}$.

These are the equations of motion:

$$
\begin{aligned}
& \left(m_{p}+m_{v}+m_{r}\right) \ddot{y}_{p}-\left(m_{v}+m_{r}\right) h_{v} \ddot{\varphi}_{p} \sin \varphi_{p}+m_{r} x_{r} \ddot{\varphi}_{v} \cos \varphi_{v}- \\
& -\left(m_{v}+m_{r}\right) h_{v} \dot{\varphi}_{p}^{2} \cos \varphi_{p}-m_{r} x_{r} \dot{\varphi}_{v}^{2} \sin \vartheta_{v}+m_{r} \dot{x}_{r} \dot{\varphi}_{v} \cos \varphi_{v}+ \\
& +k_{11} \lambda_{11}+k_{12} \lambda_{12}-c_{11} \dot{\lambda}_{11}-c_{12} \dot{\lambda}_{12}=-\left(m_{p}+m_{v}+m_{r}\right) g, \\
& {\left[I_{p}+I_{r_{z r}}+I_{v}+\left(m_{v}+m_{r}\right) h_{v}^{2}\right] \ddot{\varphi}_{p}+\left[I_{r_{z r}}+m_{r} h_{v} x_{r} \times\right.} \\
& \left.\times\left(\cos \varphi_{p} \sin \varphi_{v}-\sin \varphi_{p} \cos \varphi_{v}\right)\right] \ddot{\varphi}_{v}-\left(m_{v}+m_{r}\right) \times \\
& \times h_{v} \ddot{y}_{p} \sin \varphi_{p}-m_{r} h_{v} \ddot{x}_{r}\left(\cos \varphi_{p} \cos \varphi_{v}+\sin \varphi_{p} \sin \varphi_{v}\right)+ \\
& +2 m_{r} h_{v} \dot{x}_{r} \dot{\varphi}_{p} \sin \varphi_{p} \cos \varphi_{v}-2 m_{r} h_{v} \dot{x}_{r} \dot{\varphi}_{v} \sin \varphi_{p} \cos \varphi_{v}+ \\
& +m_{r} h_{v} x_{r} \dot{\varphi}_{v}^{2}\left(\cos \varphi_{p} \cos \varphi_{v}-\sin \varphi_{p} \sin \varphi_{v}\right)+k_{11} l_{1} \lambda_{11}- \\
& -k_{12} l_{2} \lambda_{12}-k_{31} \lambda_{31}-c_{11} l_{1} \dot{\lambda}_{11}+c_{12} l_{2} \dot{\lambda}_{12}+c_{31} \ddot{\lambda}_{31}= \\
& =\left(m_{v}+m_{r}\right) g h_{v} \sin \left(\varphi_{p}+\varphi_{p s t}\right) \text {, } \\
& \left(I_{v}+I_{r_{z r}}+m_{r} x_{r}^{2}\right) \ddot{\varphi}_{v}+m_{r} x_{r} \ddot{y}_{p} \cos \varphi_{v}+\left[I_{v}+I_{r_{z r}}+\right. \\
& \left.+m_{r} h_{v} x_{r}\left(\cos \varphi_{p} \sin \varphi_{v}-\sin \varphi_{p} \cos \varphi_{v}\right)\right] \ddot{\varphi}_{p}+ \\
& +2 m_{r} x_{r} \dot{x}_{r} \dot{\varphi}_{v}+m_{r} h_{v} x_{r} \dot{\varphi}_{p}^{2}\left(\sin \varphi_{p} \sin \varphi_{v}+\right. \\
& \left.+\cos \varphi_{p} \cos \varphi_{v}\right)+k_{31} \lambda_{31}-c_{31} \lambda_{31}=-m_{r} g x_{r} \cos \left(\varphi_{v}+\varphi_{v s t}\right) \text {, } \\
& m_{r} x_{r}-m_{r} h_{v} \ddot{\varphi}_{r}\left(\cos \varphi_{p} \cos \varphi_{v}+\sin \varphi_{p} \sin \varphi_{v}\right)+ \\
& +m_{r} \ddot{y}_{p} \sin \varphi_{p}+m_{r} h_{v} \dot{\varphi}_{p}^{2}\left(\sin \varphi_{p} \cos \varphi_{v}-\cos \varphi_{p} \sin \varphi_{v}\right)+ \\
& +m_{r} x_{r} \dot{\varphi}_{v}^{2}=-m_{r} g \sin \left(\varphi_{v}+\varphi_{v s t}\right)+P_{r} \text {, }
\end{aligned}
$$

where: $\lambda_{11}=y_{p}+y_{p s t}+l_{1}\left(\varphi_{p}+\varphi_{p s t}\right)-y_{p 11}$,

$$
\begin{aligned}
& \lambda_{12}=y_{p}+y_{p s t}-l_{2}\left(\varphi_{p}+\varphi_{p s t}\right)-y_{p 12}, \lambda_{31}=\varphi_{v}+\varphi_{v s t}-\varphi_{p}+ \\
& +\varphi_{p s t}, \quad \dot{\lambda}_{11}=y_{p}+l_{1} \dot{\varphi}_{p}-y_{p 11}, \dot{\lambda}_{12}=\dot{y}_{p}-l_{2} \dot{\varphi}_{2}-y_{p 12}, \\
& \dot{\lambda}_{31}=\dot{\varphi}_{v}-\dot{\varphi}_{p} .
\end{aligned}
$$

$P_{r}$ is the thrust of the missile motor; $M_{r}$ is the torque generated by the missile motor. In the equations of motion of the actuator, three displacements occur in vertical plane of the stand $y_{p s t}, \varphi_{p s t}$, and sight $\varphi_{v s t}$. Equations of static equilibrium are:

$$
\begin{aligned}
& k_{11}\left(y_{p s t}+l_{1} \varphi_{p s t}\right)+k_{12}\left(y_{p s t}-l_{2} \varphi_{p s t}\right)+ \\
& +\left(m_{p}+m_{v}+m_{r}\right) g=0, \\
& k_{11} l_{1}\left(y_{p s t}+l_{1} \varphi_{p s t}\right)-k_{12} l_{2}\left(y_{p s t}-l_{2} \varphi_{p s t}\right)- \\
& -k_{31}\left(\varphi_{v s t}+\varphi_{p s t}\right)-\left(m_{v}+m_{r}\right) g h_{v} \sin \varphi_{p s t}=0, \\
& k_{31}\left(\varphi_{v s t}+\varphi_{p s t}\right)=0 .
\end{aligned}
$$

The mathematical model can be classified as a coupled system with time-varying coefficients determined, with four degrees of freedom [10]. This model is consistent with experimental studies. Also, this mathematical model can be adopted for other short-range air defense systems.

\section{Simulation of the dynamic process}

Simulation of the dynamic processes has been made according to the physical and mathematical models. The numerical simulation of the dynamic processes with MATLAB Simulink software has been done. The model's simulation in two stages has been done. In the first stage, all four motion equations and in the second stage three motions were used. The two simulations have been done because when the missile leaves the container, there is no need to assess movement and mass of the missile.

Table 1

Input parameters in the dynamic process model

\begin{tabular}{|c|c|c|}
\hline Parameter & Value & Measurement unit \\
\hline$m_{p}$ & 107 & $\mathrm{~kg}$ \\
\hline$m_{v}$ & 41 & $\mathrm{~kg}$ \\
\hline$m_{r}$ & 17 & $\mathrm{~kg}$ \\
\hline$l_{p 1}$ & 0.74 & $\mathrm{~m}$ \\
\hline$l_{p 2}$ & 0.5 & $\mathrm{~m}$ \\
\hline$h_{v}$ & 0.6 & $\mathrm{~m}$ \\
\hline$I_{1}$ & 12.884 & $\mathrm{~kg} \mathrm{~m}^{3}$ \\
\hline$I_{2}$ & 8.948 & $\mathrm{~kg} \mathrm{~m}^{3}$ \\
\hline$I_{p}$ & 3.936 & $\mathrm{~kg} \mathrm{~m}^{3}$ \\
\hline$I_{v}$ & 3.072 & $\mathrm{~kg} \mathrm{~m}^{3}$ \\
\hline$I_{r z}$ & 5.876 & $\mathrm{~kg} \mathrm{~m}^{3}$ \\
\hline$I_{r x}$ & 0.036 & $\mathrm{~kg} \mathrm{~m}^{3}$ \\
\hline
\end{tabular}

During the simulation, it was evaluated that the stand is standing on the solid body, and on the stand is the operator. The whole simulation lasted for $3 \mathrm{~s}$ because, as we can see from the graphs obtained during the study, the vibrations of the whole system disappear after $3 \mathrm{~s}$.

The calculation of the missile displacement (Fig. 4), took just $0.05 \mathrm{~s}$, because the missile leaves container after $0.05 \mathrm{~s}$. Displacement of missile was about $1.1 \mathrm{~m}$ in launching tube. 
During the first stage, maximum velocity of the missile in the launching tube was $49 \mathrm{~m} / \mathrm{s}$ within $0.05 \mathrm{~s}$ (Fig. 5). The actual missile velocity and time when the missile leaves the container can be obtained from the missile producer manuals.

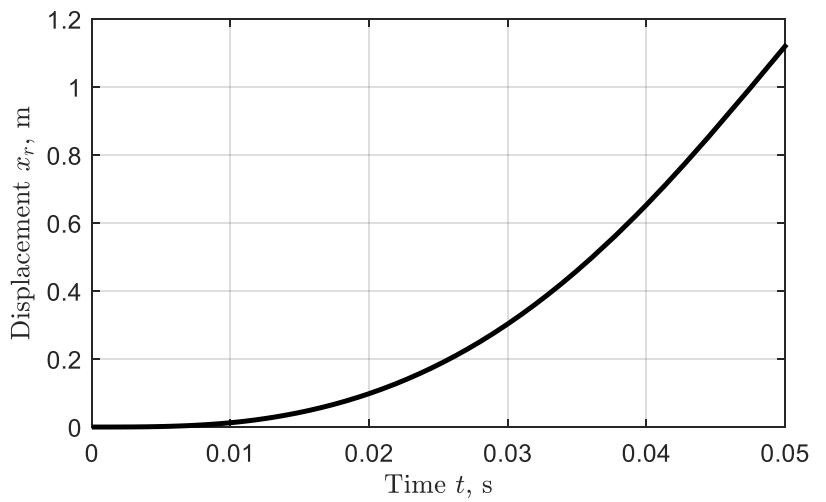

Fig. 4 Missile displacement in the launching tube

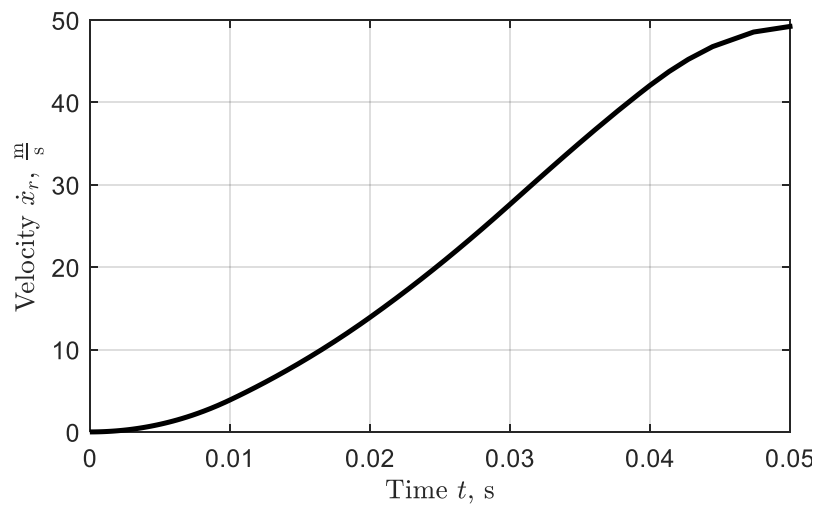

Fig. 5 Missile velocity in the launching tube

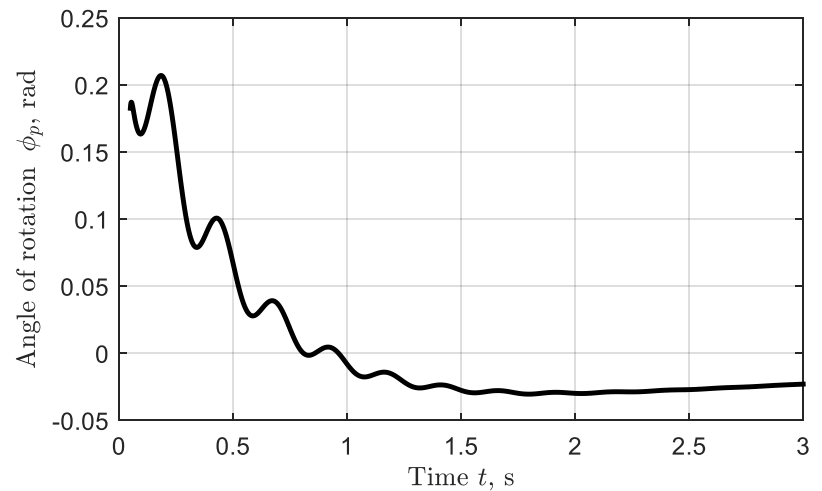

Fig. 6 Graph of rotation angle of the stand

From the graphics (Fig. 6), it can be identified that stand after the missile launch starts vibrating. Duration of angular vibrations of the launcher is approximately $2 \mathrm{sec}$ onds. Maximum angle of rotation of stand is $0.21 \mathrm{rad}$.

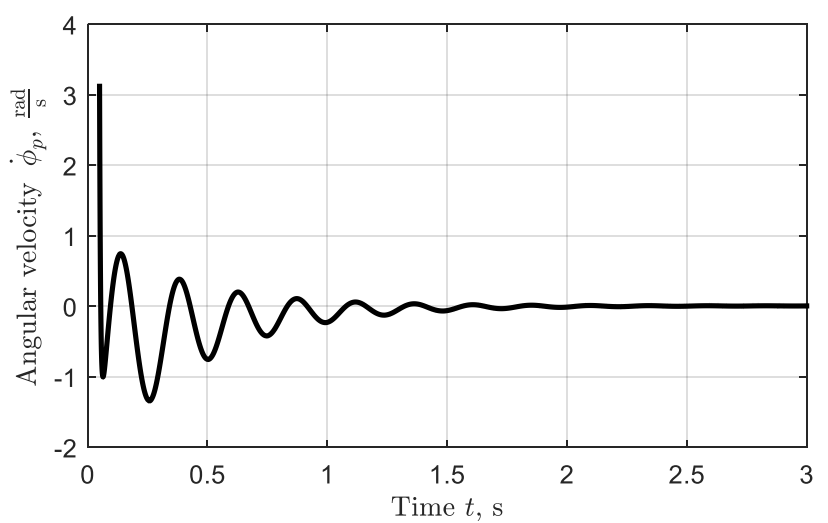

Fig. 7 Graph of angular velocity of the stand

From the graphs (Fig. 7), it can be identified that the angular vibrations of the stand stop after $2.0 \mathrm{~s}$. Maximum angular velocity of stand is $3.1 \mathrm{rad} / \mathrm{s}$.

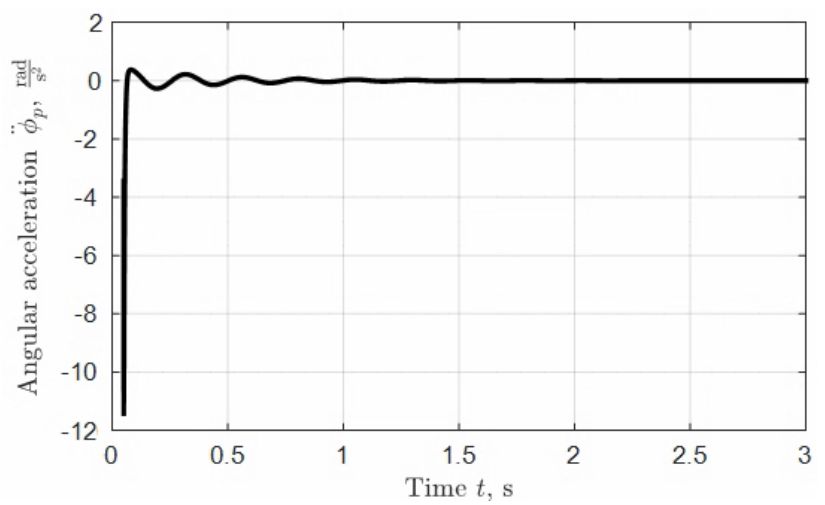

Fig. 8 Graph of angular acceleration of the stand

Angular acceleration of the stand (Fig. 8) during the missile launch is presenting in Fig. 8. Absolute maximum angular acceleration of stand is $11.7 \mathrm{rad} / \mathrm{s}^{2}$.

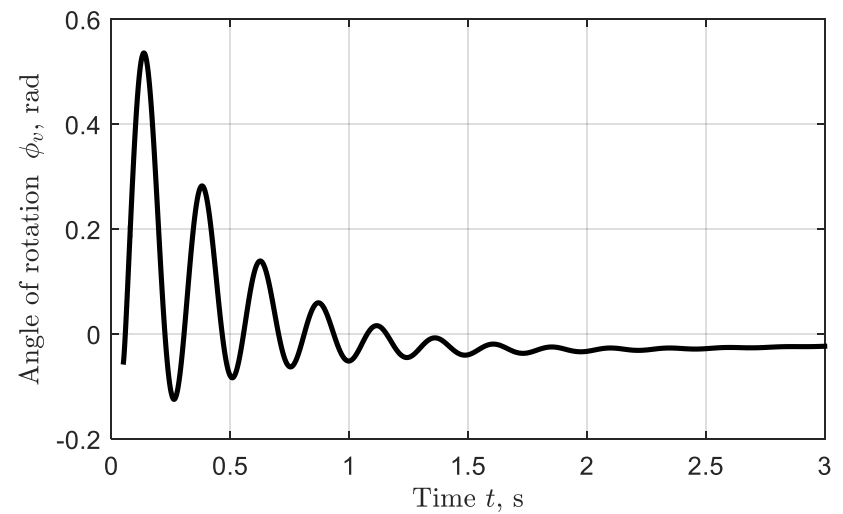

Fig. 9Graph of rotation angle of the sight

Angle of rotation of the stand (Fig. 9) in the first shooting stage firstly rises from $0 \mathrm{rad}$ till approximately 0.5 $\mathrm{rad}$. The vibration is damped and after 2.5 seconds is returning to the initial state. The angles of rotation of the sight and the stand are different due to different damping and stiffness coefficients. 


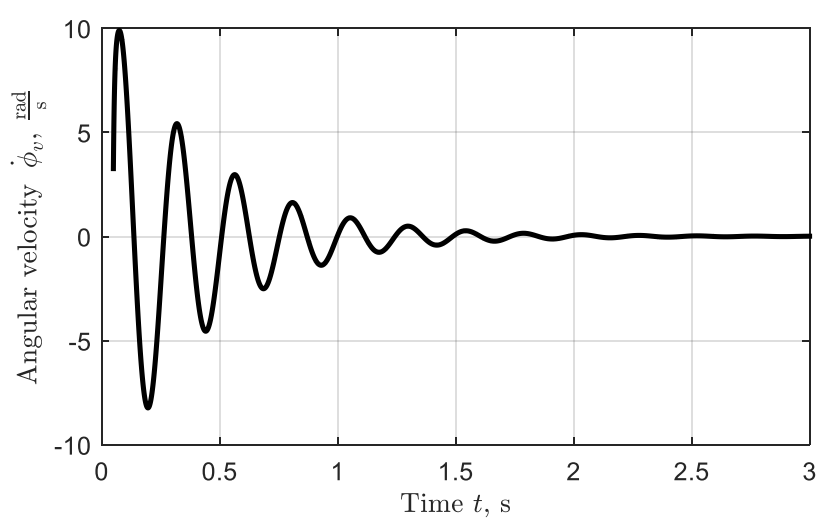

Fig. 10 Graph of angular velocity of the sight

Angular velocity of the sight (Fig. 10), in the shooting stage slightly rises and then drops down. After $2.5 \mathrm{sec}-$ onds the vibrations decrease and stops. Maximum absolute angular velocity of sight is $10 \mathrm{rad} / \mathrm{s}$.

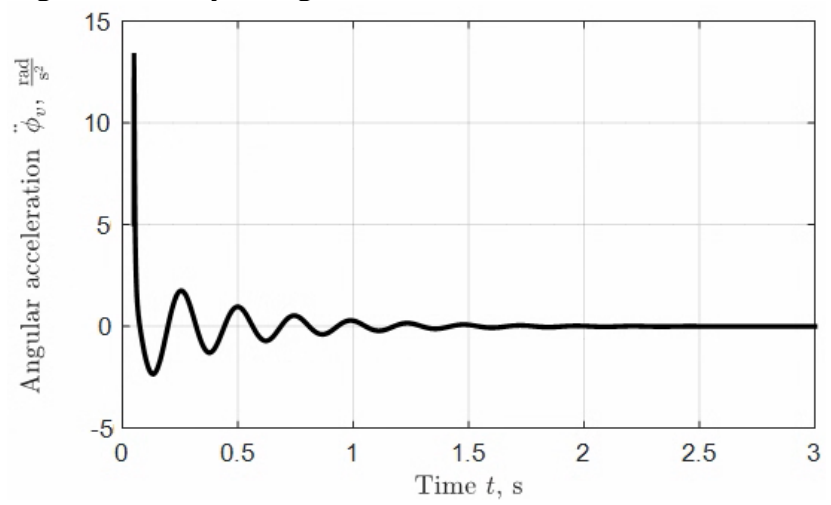

Fig. 11Graph of angular acceleration of the sight

Angular acceleration of the sight (Fig. 11) in the first shooting stage stops approximately within $2 \mathrm{~s}$. Maximum absolute angular acceleration of sight is $13.4 \mathrm{rad} / \mathrm{s}^{2}$.

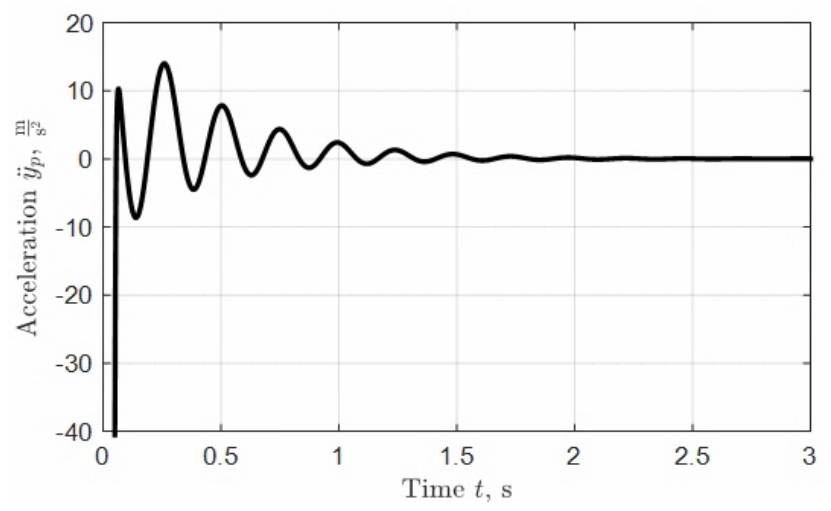

Fig. 12 Graph of absolute acceleration of the stand

Acceleration of the stand (Fig. 12) after the shot immediately drops down and then suddenly returns to the positive value. Maximum absolute acceleration of stand is $41 \mathrm{~m} / \mathrm{s}^{2}$. The vibrations occur due to the missile engine. The vibration frequency is $4 \mathrm{~Hz}$.

\section{Experimental research}

Experimental studies to test the performance of the physical and mathematical models were performed. Piezoelectric Accelerometers were placed on the sight and the on the stand. On the sight Triaxial Piezoelectric Accelerometer
Brüel \& Kjær Type 4506 was placed. On the stand Piezoelectric Accelerometer Brüel \& Kjær Type 4507 was placed. The Piezoelectric Accelerometer placement on the sight is shown in Fig. 13.

Analysis of the data collected by the Multi-analyzer System Brüel \& Kjær Type 3560C was done with PULSE LabShop software. The experimental research of the acceleration of stand was performed, in order to check theoretical research results.

From the graph (Fig. 14), it can be identified that the vibration frequency is $4.2 \mathrm{~Hz}$. It can be stated that response of the stand obtained experimentally is close to the response obtained by theoretical research (Figs.12, 14) what proves adequacy of mathematical model.

\section{Conclusions}

In this article the first phase of the missile launches of the short-range air defense system RBS-70 was analyzed.

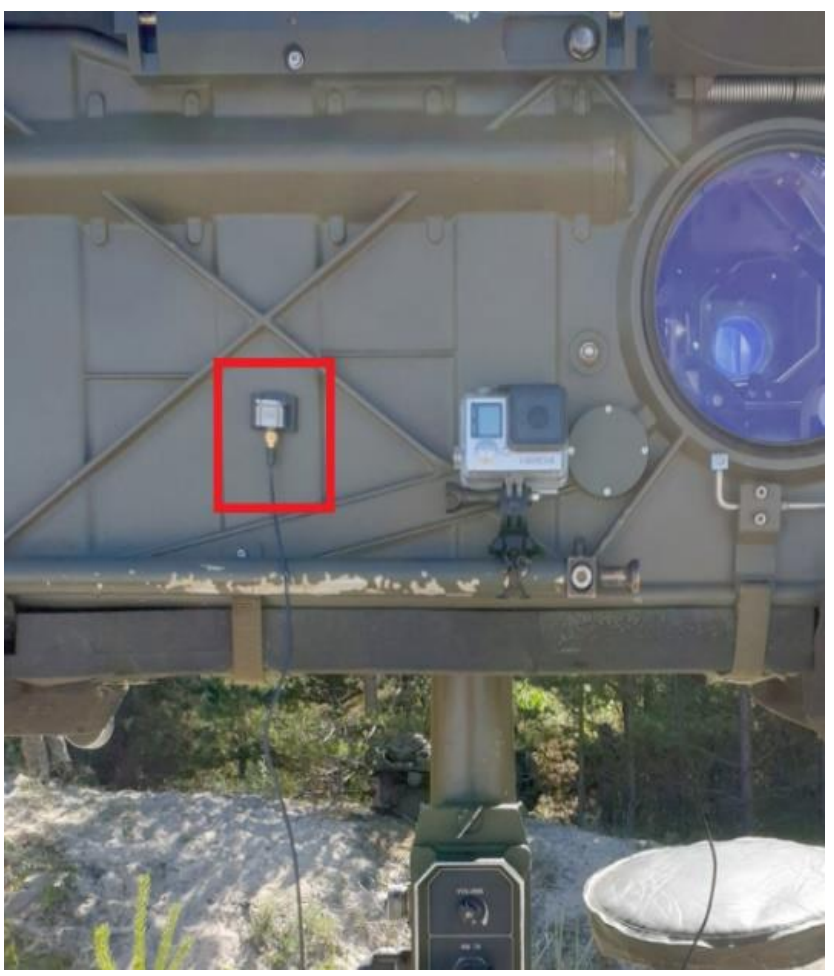

Fig. 13 Piezoelectric accelerometer on the sight

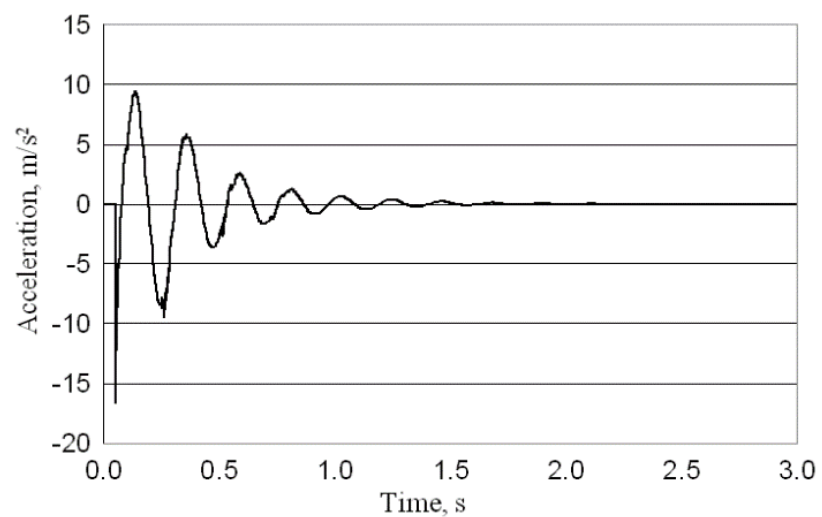

Fig. 14 Absolute acceleration of the stand determined experimentally

After the theoretical research, theoretical model of the first phase of the missile launch of the short-range air 
defense system have been made. The equations of motion of the system were derived based on the formulated physical model.

Computer simulation and analysis of physical phenomena, considering the analytical dependences related to the movement of the system were performed. System movements during missile launch and their effects on the launcher based on the initial system parameters were determined.

The results suggest that in the first phase of the missile launch, the dynamic displacement coefficients are very small because the sight just put out the missile from the container. When the missile is fired from the container, only the first missile engine is running. The first engine's purpose is to fire a missile from a container. When the missile leaves the container, the second engine starts running.

To test the performance of the physical and mathematical models, the experimental studies were performed. Piezoelectric accelerometers were placed on the sight and on the stand. The experimental calculation to determine the acceleration of the stand has been done. The developed model allows to perform detailed analysis of dynamics of the launcher.

\section{References}

1. Dugalic, A. 2018. NG stand mechanical interface analysis for vehicle integrated RBS 70 NG [online] URN: urn:nbn:se:kau:diva-68635 [accessed 12 Dec. 2020]. Available from Internet: http://www.diva-potal.org/sma sh/get/diva2:1236120/FULLTEXT02.pdf.

2. Saab. RBS 70 NG [online] [accessed 4 Feb. 2021]. Available from Internet: https://w ww.saab.com/products/rbs-70-ng.

Saab. RBS 70 NG - Brazil's Choice of Ground-Based Air Defence for Every Threat [online] [accessed 4 Feb. 2021]. Available from Internet: https://www.youtube.c $\mathrm{om} /$ watch?v=bV2-vxG2LLQ.

3. Biessonov A. P. 1967. Basis of the Dynamics of Mechanisms with a Variable Links Mass, Science, Moscow, $279 \mathrm{p}$.

4. Inman D. J. 2006. Vibration with Control, John Wiley \& Sons, Ltd. ISBN: 0-470-01051-7, 376 p.

5. Žyluk A. 2014. Numerical simulation of the effect of wind on the missile motion, Journal of Theoretical and Applied Mechanics, 335-344 p.

6. Zhang D.; Xiao J. 2005. A dynamic model for rocket launcher with coupled rigid and flexible motion, Journal applied mathematics and mechanics, 609-617 p.
7. Dziopa Z.; Krzysztofik I.; Koruba Z. 2010. An analysis of the dynamics of a launcher-missile system on a moveable base. Bulletin of the Polish Academy of science technical science, 645-650 p. http://dx.doi.org/10.2478/v10175-010-0068-5.

8. National Aeronautics and Space Administration. Determining center of gravity - cg. [online] [accessed 4 Feb. 2021]. Available from Internet: https://www.grc .nasa.gov/www/k-12/rocket/rktcg. Html.

9. De Silva C. W. 2007. Vibration Fundamentals and Practice. Taylor \& Francis Group, Boca Raton, London-New York, ISBN 0-8493-1808-4, 957 p.

10. Yang J.; Wang Z. 2012. Numerical Simulation of Launch Tube Based on Container - type Missile Launch Technology, International Conference on Advances in Computational Modeling and Simulation, 302-307p.

\section{A. Fedaravičius, K. Jasas, E. Sližys, A. Survila \\ MODELING OF THE DYNAMIC PROCESSES FOR THE SHORT-RANGE AIR DEFENSE SYSTEM}

S u m m a r y

Armament systems such as guns, launchers simulators are effective tool for training armed forces personnel. A firearm is a complex biomechanical system, the best quality of training is achieved when training in a simulator, repeating the dynamic processes of the weapon by simulating the perception of real weapon use (feeling). The paper investigates the dynamic and stability properties of the shortrange air defense system RBS-70. The RBS-70 short-range air defense system is designed to combat low-flying air targets. The purpose of this paper is to present the physical and mathematical models and numerical dynamic simulation results of the launcher in the first phase of missile flight. The theoretical model was formulated in vertical plane and verified by the numerical simulation.

Keywords: short-range air defense system, military simulator, dynamics process.

Received June 11, 2021

Accepted February 04, 2022 